\title{
Applicability of the Vibration Correlation Technique for Estimation of the Buckling Load in Axial Compression of Cylindrical Isotropic Shells with and without Circular Cutouts
}

\author{
Eduards Skukis, ${ }^{1}$ Olgerts Ozolins, ${ }^{1}$ Janis Andersons, ${ }^{2}$ \\ Kaspars Kalnins, ${ }^{1}$ and Mariano A. Arbelo ${ }^{3}$ \\ ${ }^{1}$ Riga Technical University (RTU), Institute of Materials and Structures, Kipsalas 6A, Riga, LV-1048, Latvia \\ ${ }^{2}$ University of Latvia (LU), Institute for Mechanics of Materials, Aizkraukles 23, Riga, LV-1006, Latvia \\ ${ }^{3}$ Aeronautics Institute of Technology (ITA), 12228-900 Sao Jose dos Campos, SP, Brazil \\ Correspondence should be addressed to Eduards Skukis; edskukis@gmail.com
}

Received 28 August 2017; Accepted 5 November 2017; Published 29 November 2017

Academic Editor: Nerio Tullini

Copyright (C) 2017 Eduards Skukis et al. This is an open access article distributed under the Creative Commons Attribution License, which permits unrestricted use, distribution, and reproduction in any medium, provided the original work is properly cited.

Applicability of the vibration correlation technique (VCT) for nondestructive evaluation of the axial buckling load is considered. Thin-walled cylindrical shells with and without circular cutouts have been produced by adhesive overlap bonding from a sheet of aluminium alloy. Both mid-surface and bond-line imperfections of initial shell geometry have been characterized by a laser scanner. Vibration response of shells under axial compression has been monitored to experimentally determine the variation of the first eigenfrequency as a function of applied load. It is demonstrated that VCT provides reliable estimate of buckling load when structure has been loaded up to at least $60 \%$ of the critical load. This applies to uncut structures where global failure mode is governing collapse of the structure. By contrast, a local buckling in the vicinity of a cutout could not be predicted by VCT means. Nevertheless, it has been demonstrated that certain reinforcement around cutout may enable the global failure mode and corresponding reliability of VCT estimation.

\section{Introduction}

Thin-walled shell structures are extensively employed in applications where minimization of weight is of primary importance (e.g., in aerospace). Load-carrying capacity of such structures in compression is typically governed by buckling. The imperfection sensitivity exhibited by cylindrical shells renders particular emphasis on their design against instability in axial compression. Therefore, robust design approaches are being developed and validated, such as single perturbation load, single perturbation displacement, single boundary perturbation approaches, and their modifications (see, e.g., [1-7]) in order to replace the existing overconservative design guidelines.

Nevertheless, the possibility of a nondestructive evaluation of buckling load is indispensable for proof-testing of structures and also instrumental in validation of theoretical stability analyses. Vibration correlation technique (VCT) is such a nondestructive vibration test method that allows estimating the buckling load based on experimentally obtained variation of a natural frequency with the applied load as detailed in $[8,9]$. It should be noted that VCT can also be applied to determine the actual in situ boundary conditions of structures that can greatly enhance the accuracy of numerical prediction of buckling load [8]. VCTs have generally reached maturity for columns and plates [8], although further refinements are still being developed (e.g., for curved panels) [10]. Moreover, further work is still needed on the validation of the VCT in order to attain industrial applicability for shell structures $[10,11]$.

Application of VCT is usually based on a theoretically or experimentally determined functional form of the vibration frequency variation with the applied load that is fitted to the test data and extrapolated to estimate the critical buckling load. It has been demonstrated that, as for a variety of other structures possessing similar buckling and vibration modes, 
the natural frequency squared is a linear function of the applied axial load also for perfect cylindrical shells $[8,9]$. Although low-frequency vibration modes of closely stiffened shells are very similar to their buckling modes, the experimental dependence of frequency squared on axial load was found to exhibit a marked drop in the natural frequency at relatively high loads approaching buckling $[8,10]$. The leading role of initial geometrical imperfections in causing such a vibration response has been highlighted by shell models of various complexities [11-13]. Semiempirical relations have been proposed and verified for extraction of buckling load from the experimental natural frequency versus axial load data of closely stiffened shells as discussed in $[8,10,12,14,15]$. In particular, using a simplified model of shell, Souza et al. $[12,15]$ suggested that $(1-p)^{2}$ should be a linear function of $1-f^{4}$; it can be presented analytically as [10]

$$
(1-p)^{2}+\left(1-\xi^{2}\right)\left(1-f^{4}\right)=1,
$$

where the nondimensional load parameter $p=P / P_{\mathrm{cr}}$ is given by the applied axial load $P$ normalized by the buckling load of a perfect shell $P_{\mathrm{cr}}$, and the frequency parameter $f=f_{m} / f_{0}$ is the ratio of the vibration frequency $f_{m}$ measured at load $P$ and the natural frequency of the unloaded shell $f_{0}$. By fitting (1) to the vibration test results at relatively low loads, the knock-down parameter $\xi$ is evaluated and the buckling load is estimated as

$$
P_{\text {pred }}=(1-\xi) P_{\mathrm{cr}}
$$

that is, as the load at $f=0$ from (1).

Unlike closely stiffened shells, unstiffened (monocoque) cylindrical shells exhibit buckling modes that differ from the fundamental vibration modes. Therefore, the VCT methods developed for closely stiffened shells may not be directly transferable to the unstiffened ones. Applicability of VCT to unstiffened stainless steel cylinders was explored in [16] employing linear and quadratic fitting polynomials for vibration frequency squared as a function of axial load, with encouraging but inconclusive preliminary results. The VCT proposed by Souza et al. [12, 15] was applied to unstiffened cylindrical shells by Arbelo et al. [17] using extensive numerical simulations. Negative values of the parameter $\xi^{2}$ in (1) were obtained having no physical meaning, thus invalidating the approach $[12,15]$ for unstiffened cylindrical shells. However, it inspired a modification of VCT as follows [17]. It was proposed to approximate the $(1-p)^{2}$ data as a second-order polynomial of $1-f^{2}$. The minimum value of $(1-p)^{2}$ determined using this approximation was associated with the parameter $\xi^{2}$ characterizing the reduction of loadcarrying capacity of unstiffened cylindrical shells due to the initial imperfections. Having thus determined the value of $\xi^{2}$, the buckling load is estimated by (2).

The modified VCT of Arbelo et al. [17] has been extensively validated for thin-walled unstiffened cylindrical shells produced from carbon/epoxy [18-20], stainless steel [19], and aluminium [21] demonstrating its capacity of determining the axial bucking load via nondestructive tests. However, common applications from aerospace to civil structures require isotropic shell structures to be accommodated with local cutouts. The principal aim of the current study is evaluation of the applicability of the modified VCT for estimation of buckling load of isotropic unstiffened cylindrical shells weakened by cutouts in the form of an open circular hole. Furthermore, the accuracy of nonlinear FEM analysis of instability using experimentally determined geometrical imperfection data of the shells and the effect of boundary condition model are evaluated.

\section{Test Specimens}

2.1. Manufacturing of Cylinders. A total of twelve cylindrical shells having nominal diameter $D_{\text {shell }}=500 \mathrm{~mm}$ and free height $H_{\text {shell }}=460 \mathrm{~mm}$ were manufactured from $0.5 \mathrm{~mm}$ thick EN AW 6082 T6 aluminium alloy sheet. The shells designated as R29-R32, R34, and R40 had no cutouts. Shells $\mathrm{R} 33, \mathrm{R} 35$, and R36 featured circular cutouts of diameter $\mathrm{D}=$ $50 \mathrm{~mm}, 80 \mathrm{~mm}$, and $30 \mathrm{~mm}$, respectively. Shell R37, in addition to a cutout of $30 \mathrm{~mm}$ diameter, was strengthened by a reinforcement ply made from the same sheet in the shape of $20 \mathrm{~mm}$ wide ring, with outer diameter $50 \mathrm{~mm}$, attached around the cutout. Shells R38 and R39 had $80 \mathrm{~mm}$ diameter cutouts with 20 and $10 \mathrm{~mm}$ wide reinforcement rings, respectively. A summary of the test specimen geometry is presented in Table 1.

When prototyping the shells at RTU premises, the aluminium sheets were cut and machined manually before bonding with Araldite ${ }^{\circledR} 2011$ universal two-component epoxy structural adhesive via a $25 \mathrm{~mm}$ overlap longitudinal joint and cured at room temperature. Both the opposite edges of a sheet to be joined were unsymmetrically taper-machined to ensure a uniform thickness distribution across the $25 \mathrm{~mm}$ wide overlap joint. Abrasive treatment was applied to the joint surfaces before bonding. Adhesive bonding was carried out on a steel mandrel of $500 \mathrm{~mm}$ diameter using vacuum bag to press the aluminium sheet to the mandrel. The joint area was pressed with clamps against the mandrel surface to facilitate uniform bonding. The average bond thickness amounted to $0.85 \mathrm{~mm}$ for shells R29 and R30, which were manufactured earlier during EC FP7 project DESICOS employing the same manufacturing technique [21], and $0.75 \mathrm{~mm}$ for the rest of shells. The subsequent stages of joining the sheet edges described above are illustrated in Figure 1.

The cutouts were machined upon production of the shells. All the cutouts were located in the shell mid-height and shifted by about $90^{\circ}$ circumferentially with respect to the bonding line. The reinforced cutouts were manufactured by bonding the reinforcement ring to the assembled shell, while it was on the steel mandrel. The rings were made of the same aluminium sheet and adhesively bonded by Araldite 2011 adhesive used for shell bonding. The shell cutout was machined the same way as for unreinforced cutouts, matching the internal diameter of reinforcement ring. Cutout milling was performed employing hand-held tungsten carbide burr. The cutouts thus produced, both lacking reinforcement and reinforced by rings of different width, are shown in Figure 2.

Machining of cutouts in the already assembled shells allowed performing initial geometry scans of the shells before 

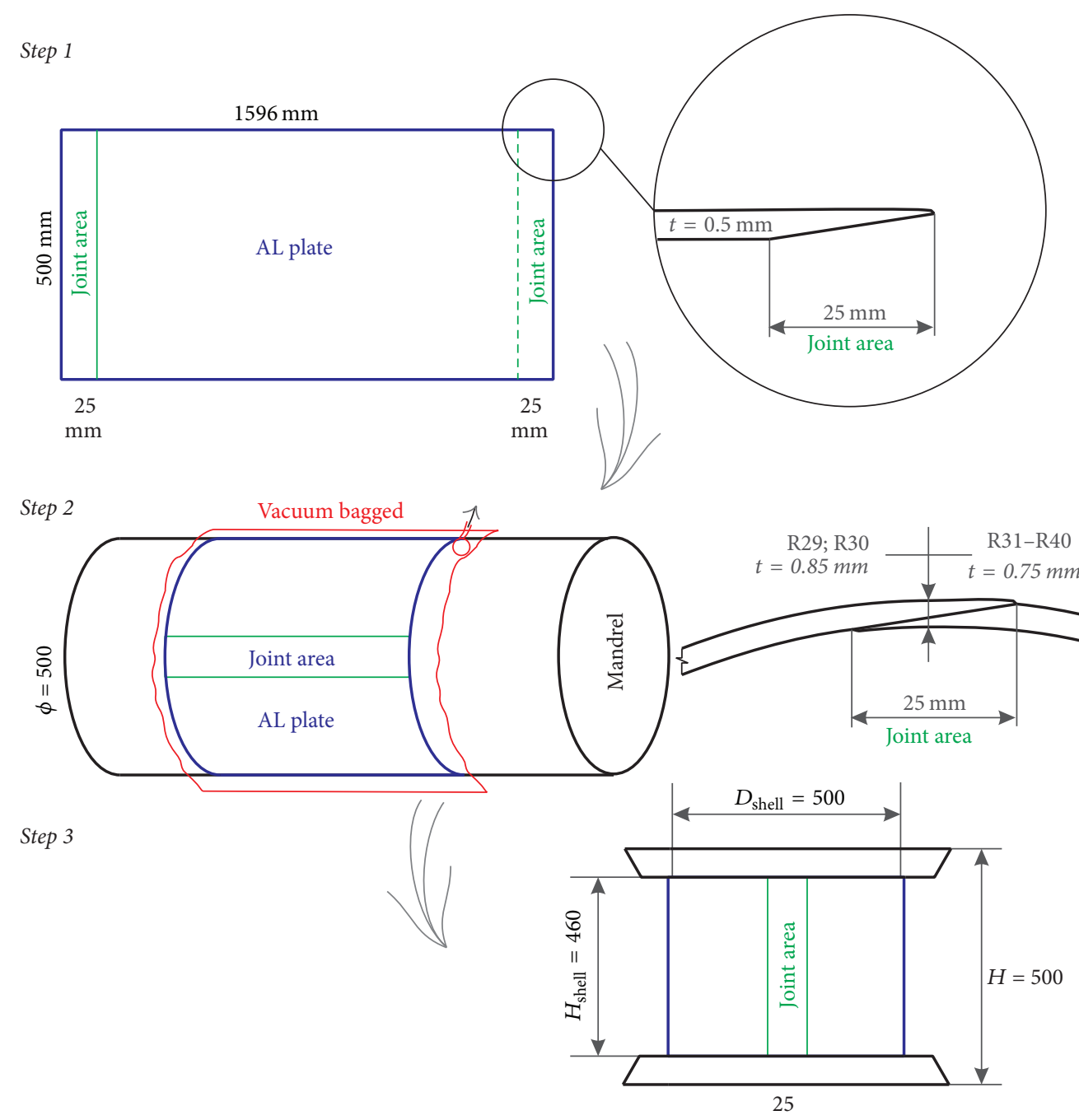

FIGURE 1: Subsequent stages for producing of an adhesively bonded overlap joint: tapering of both edges at the bonding line (Step 1); aluminium sheet wrapped around a cylindrical steel mandrel, vacuum-bagged with clamped joint area (Step 2); final assembly, cylindrical shell with edge casting blocks (Step 3).

TABLE 1: Test specimens.

\begin{tabular}{|c|c|c|c|c|c|c|c|}
\hline Cylinder ID & $\begin{array}{c}\text { Nominal } \\
\text { diameter } D_{\text {shell }} \\
\end{array}$ & $\begin{array}{c}\text { Free height } \\
\quad H_{\text {shell }} \\
\end{array}$ & Thickness & $\begin{array}{l}\text { Total thickness } \\
\text { at bonded area }\end{array}$ & $\begin{array}{c}\text { Cutout diameter } \\
D \\
\end{array}$ & Reinforcement & Shimming \\
\hline $\mathrm{R} 29$ & \multirow{12}{*}{$500 \mathrm{~mm}$} & \multirow{12}{*}{$460 \mathrm{~mm}$} & \multirow{12}{*}{$0.5 \mathrm{~mm}$} & $0.85 \mathrm{~mm}$ & No cutout & No & Lower loading plate \\
\hline $\mathrm{R} 30$ & & & & $0.85 \mathrm{~mm}$ & No cutout & No & Lower loading plate \\
\hline $\mathrm{R} 31$ & & & & $0.75 \mathrm{~mm}$ & No cutout & No & No \\
\hline $\mathrm{R} 32$ & & & & $0.75 \mathrm{~mm}$ & No cutout & No & No \\
\hline R33 & & & & $0.75 \mathrm{~mm}$ & $50 \mathrm{~mm}$ & No & No \\
\hline R34 & & & & $0.75 \mathrm{~mm}$ & No cutout & No & No \\
\hline R35 & & & & $0.75 \mathrm{~mm}$ & $80 \mathrm{~mm}$ & No & No \\
\hline R36 & & & & $0.75 \mathrm{~mm}$ & $30 \mathrm{~mm}$ & No & No \\
\hline R37 & & & & $0.75 \mathrm{~mm}$ & $30 \mathrm{~mm}$ & $\begin{array}{l}20 \mathrm{~mm} \text { wide } \\
\text { ring }\end{array}$ & No \\
\hline R38 & & & & $0.75 \mathrm{~mm}$ & $80 \mathrm{~mm}$ & $\begin{array}{l}20 \mathrm{~mm} \text { wide } \\
\text { ring }\end{array}$ & No \\
\hline R39 & & & & $0.75 \mathrm{~mm}$ & $80 \mathrm{~mm}$ & $\begin{array}{l}10 \mathrm{~mm} \text { wide } \\
\text { ring }\end{array}$ & No \\
\hline $\mathrm{R} 40$ & & & & $0.75 \mathrm{~mm}$ & No cutout & No & No \\
\hline
\end{tabular}




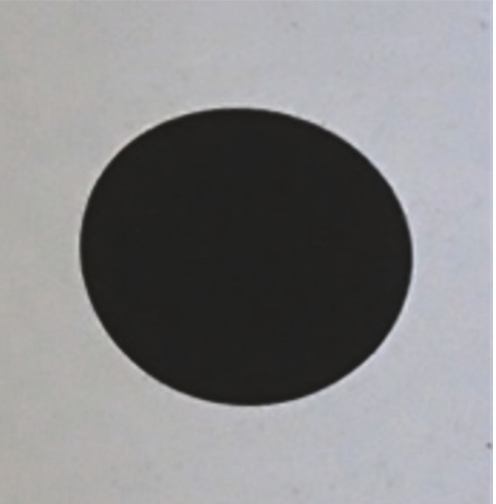

(a)

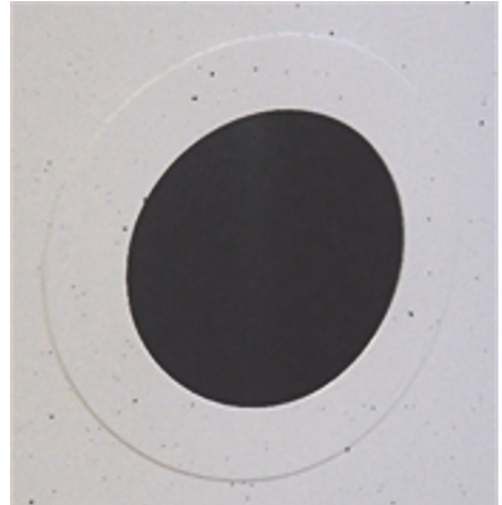

(b)

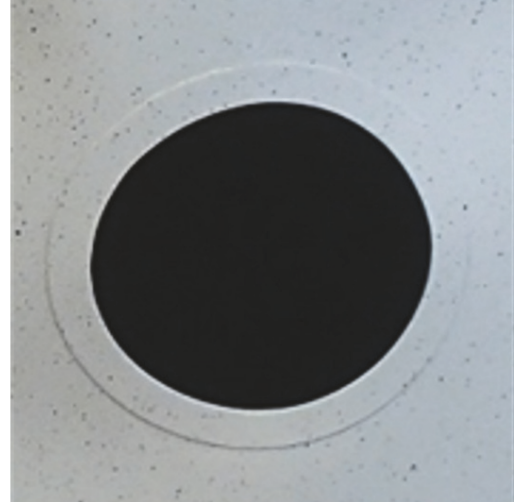

(c)

FIGURE 2: Different cutout edge conditions: unreinforced cutout (a) and cutouts with reinforcing rings of 20 (b) and 10 (c) mm width.

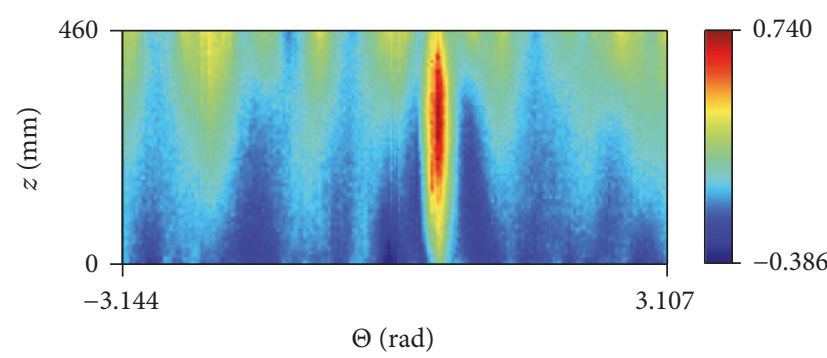

(a)

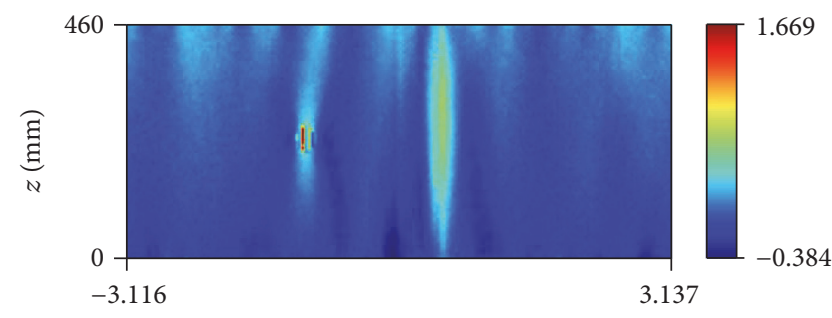

$\Theta(\mathrm{rad})$

(b)

FIGURE 3: Imperfection scans by an internal laser scanner for R36 shell before (a) and after (b) introduction of cutout.

actual cutouts were made to gather imperfection data related to manufacturing imperfection signatures.

2.2. Characterization of Geometrical Imperfections of Shells. A laser scanner (Panasonic HL-G1 sensor) was used to measure the geometric imperfections of the inner surface of all the cylinders. The laser scan was controlled using an in-house software and the data acquired were exported in real time to a text file for postprocessing.

Upon scanning, the best-fit-cylinder algorithm was applied to the raw data in order to eliminate the rigid body motion modes from the measurements. The results presented in Figure 3 show unfiltered imperfection pattern for R36 shell, captured before and after introduction of the cutout. It should be noted that the cutout area was externally covered to avoid out-of-range readings of the laser; nevertheless, one may see that both the cutout and adhesive joint areas are exhibiting the most severe imperfections.

\section{Mechanical Tests}

3.1. Characterization of the Shell Wall Material. The procedure for material characterization according to ASTM E-8M04 standard was carried out for $0.5 \mathrm{~mm}$ thick sheet of $\mathrm{EN}$ AW 6082 T6 aluminium alloy used for manufacturing of the cylindrical shells. The aim of material characterization was to determine the yield stress and ultimate stress, as well as the

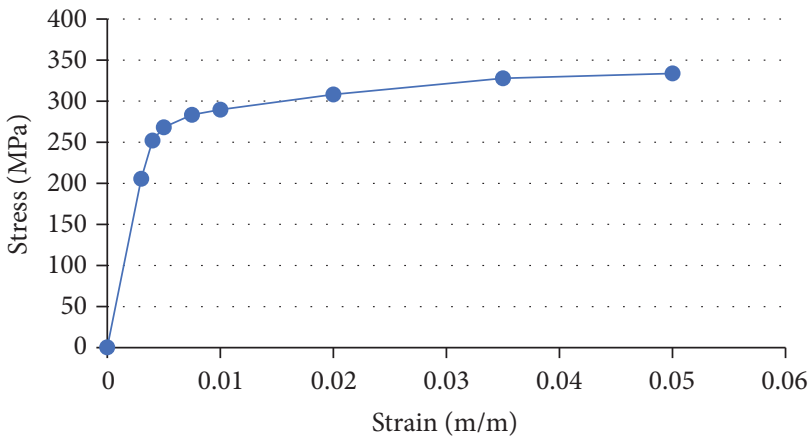

FIGURE 4: MISO curve of the aluminium sheet material with indicated experimental stress-strain data points used for its construction.

nonlinear plasticity diagram of the material to be employed in finite element analyses of buckling. Multilinear isotropic hardening (MISO) material model, exemplified in Figure 4, was established based on the experimentally obtained stressstrain curves. Typical Young's modulus value of aluminium alloys of $70 \mathrm{GPa}$ was used in the material model.

3.2. Shell Buckling Tests. Experimental buckling test set-up for shells, shown in Figure 5, comprised three LVDTs (placed around the shell at $120^{\circ}$ angular intervals) for shortening measurements, one of them aligned with the bonding line 


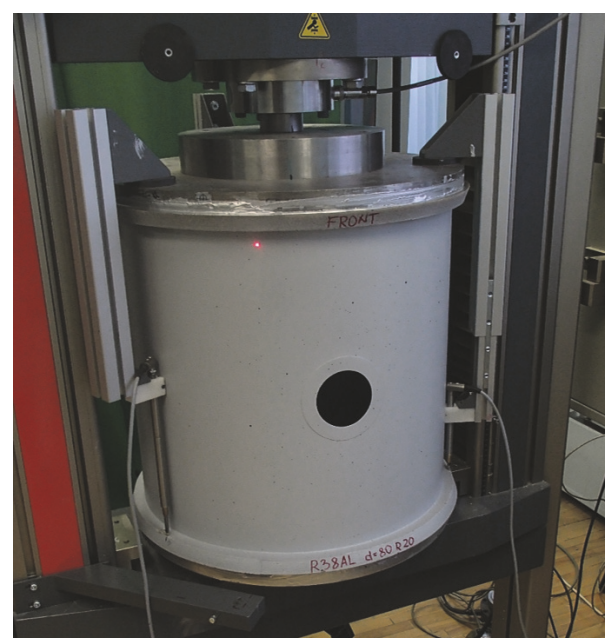

FIGURE 5: Experimental test set-up.

of the shell. Both the top and bottom edges of shells, resting on the respective machine plates, were joined to the plates by means of potting with a resin/powder filler to eliminate loading imperfections and contact surface misalignments.

For most of the cylinder tests, the bottom plate was bolted to the respective crosshead as shown in Figure 6(a). By contrast, for shells R29 and R30 the test set-up contained a shimmed interface at the lower machine plate (Figure 6(b)). Shimming was performed by placing very thin sheets of metal between the lower loading plate and the load distributing washer attached to the load frame in order to eliminate the small gaps between both surfaces, so that an even distribution of load along the cylinder's circumference was ensured. When testing the rest of cylinders, this interface was eliminated by bolting both load distributing structures directly to the load frame (Figure 6(a)).

Universal quasi-static testing machine Zwick 100 was used for the tests. Loading was introduced by incremental upper edge displacement at a rate of $0.5 \mathrm{~mm} / \mathrm{min}$. Load measurement was carried out by a single load cell located between the upper loading plate and the upper crosshead of the loading frame.

A photogrammetry based technique was used to capture the $3 \mathrm{D}$ buckling mode shape deformation pattern and to build open plots.

3.3. Characterization of Vibration Response. The universal quasi-static testing machine Zwick 100 was used to apply axial compressive load on the cylinders. Starting from zero load (i.e., unloaded shell), the compressive load was gradually increased in $2 \mathrm{kN}$ steps up to ca. $85 \%$ of the estimated buckling load. Upon each load increment, the natural frequencies and vibration modes were scanned by Polytec laser vibrometer on a grid of points distributed along a small area of the cylinder (Figure 7).

For structural excitation, a loudspeaker, placed $180^{\circ}$ opposite to the scanned area, was used and measurements were conducted in the frequency range from 200 to $400 \mathrm{~Hz}$. The scanned sector of cylinder was approximately $72^{\circ}$ wide that corresponds to $1 / 5$ of cylinder surface. The scanned area consisted of 300 grid points that presented a good trade-off between the scanning time and the level of detail of modal response. The vibration mode shapes captured by the laser vibrometer and corresponding to the first natural frequency are shown in Figure 8 overlaid onto the respective shells tested.

\section{Numerical Analyses}

Numerical simulations were performed by means of ANSYS [22] finite element code as nonlinear buckling analyses with multilinear isotropic hardening material model to allow for plasticity. Newton-Raphson large deformation solver was used to solve the shell finite element model composed of shell (SHELL281), solid (SOLID186), and multipurpose constraint (MPC184) finite elements. Two approaches of implementation of the boundary conditions were covered in the current study, namely, simplified clamped boundary conditions (CBC), which consider clamped shell edges with uniform loading by edge translation, and real case boundary conditions (RBC), consisting of modeling of the actual load introducing parts of the test set-up, connected to the shell edges by multipoint constraint element rigid beams. The basic concern of the utilization of the more complicated FE analysis model versus the simplified one was related to the particular test set-up containing a circular adapter $(25 \mathrm{~mm}$ long steel adapter stud of $63 \mathrm{~mm}$ diameter, connecting upper load transfer plate to the load cell, attached to the test frame crosshead) (see Figure 5), taking into account bending of the top and bottom load distribution plates resulting in rotation of the shell boundary region.

In the case of CBC, bottom edge of the shell was considered as clamped (i.e., the condition of all edge displacement and rotation components being equal to zero was imposed). The upper edge was considered clamped for all the rotations and displacements except that in the loading direction. Loading by displacement was applied to all the upper edge nodes.

In the case of RBC, all the set-up parts up to connection to the load cell were modeled by shell and solid finite elements representing physical interaction of the actual parts, allowing for loading edge rotation and bending of the loading plate. Clamped boundary conditions were applied on the central part of the bottom steel plate, while the shell edge was clamped to the plate, allowing for rotation. The upper loading unit was constrained in lateral directions, with displacement in the loading direction applied to all the nodes of the upper part of connector stud, thus allowing load redistribution through all the components to the shell. The respective FEM models are shown in Figure 9.

The critical buckling load of a perfect shell, needed for application of the VCT, was obtained by a linear FEM analysis of a shell lacking any imperfections and subjected to CBC.

\section{Results and Discussion}

5.1. Experimental Buckling Loads and Modes. The buckling loads and mode shapes determined for each of the specimens 


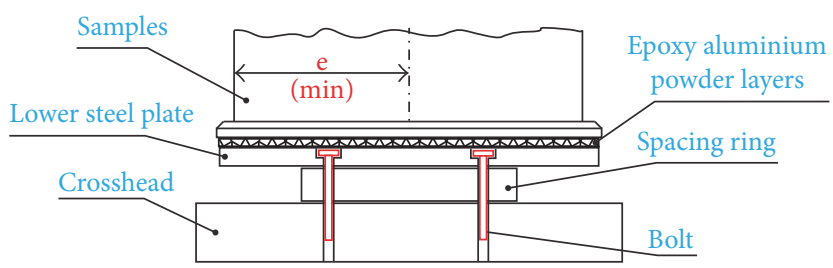

(a)

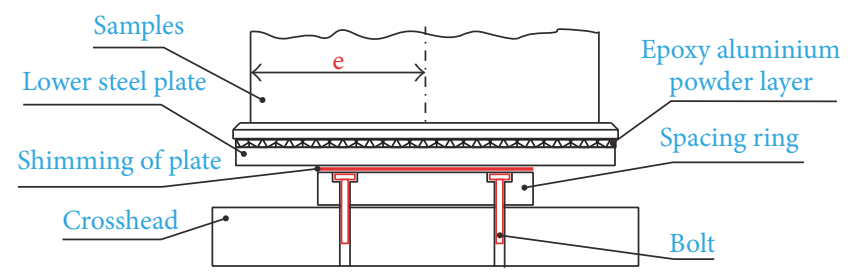

(b)

FIgURE 6: Schematic of the lower shell support for most of the specimens (a) and for shells R29 and R30 (b).

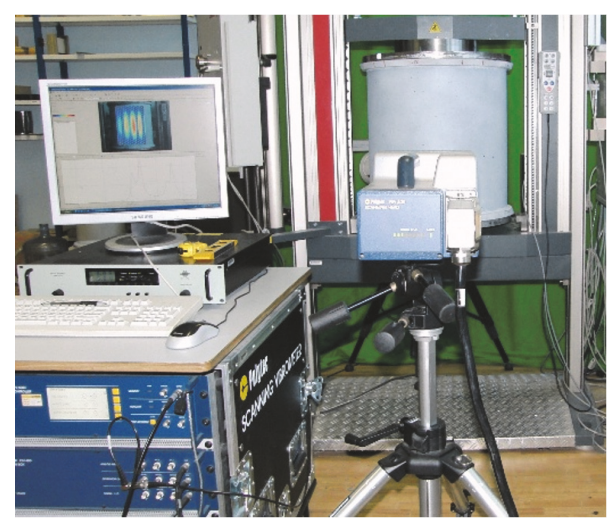

FIGURE 7: Experimental set-up for vibration tests.

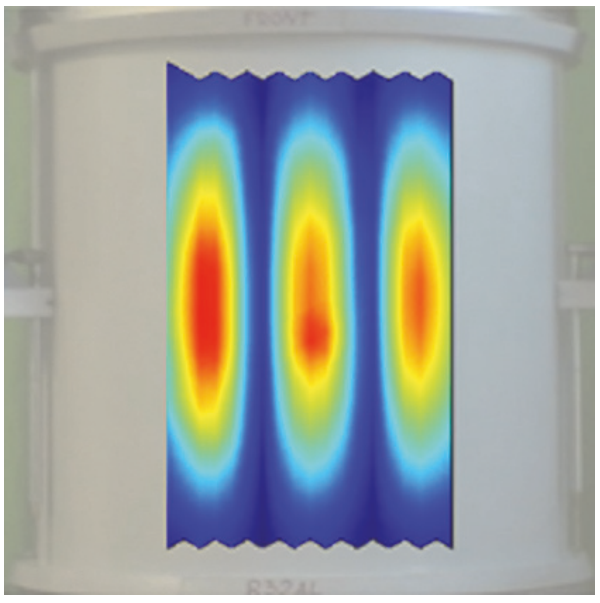

(a)

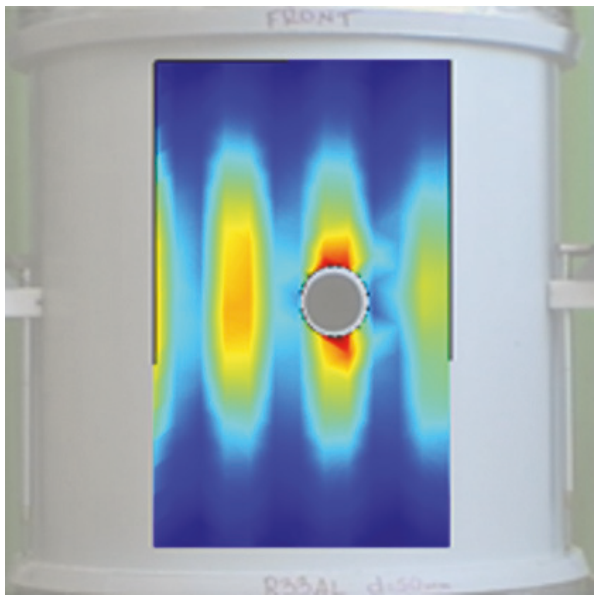

(b)

FIGURE 8: First vibration mode used in VCT of an intact cylinder (a) and a cylinder with cutout (b).
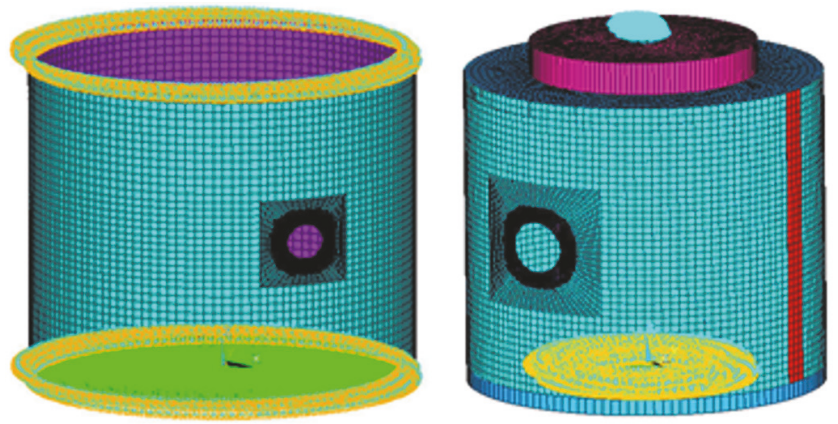

FIGURE 9: FEM models for CBC and RBC of a cylindrical shell with cutout. 
TABLE 2: Experimental buckling loads and mode shapes of intact shells.

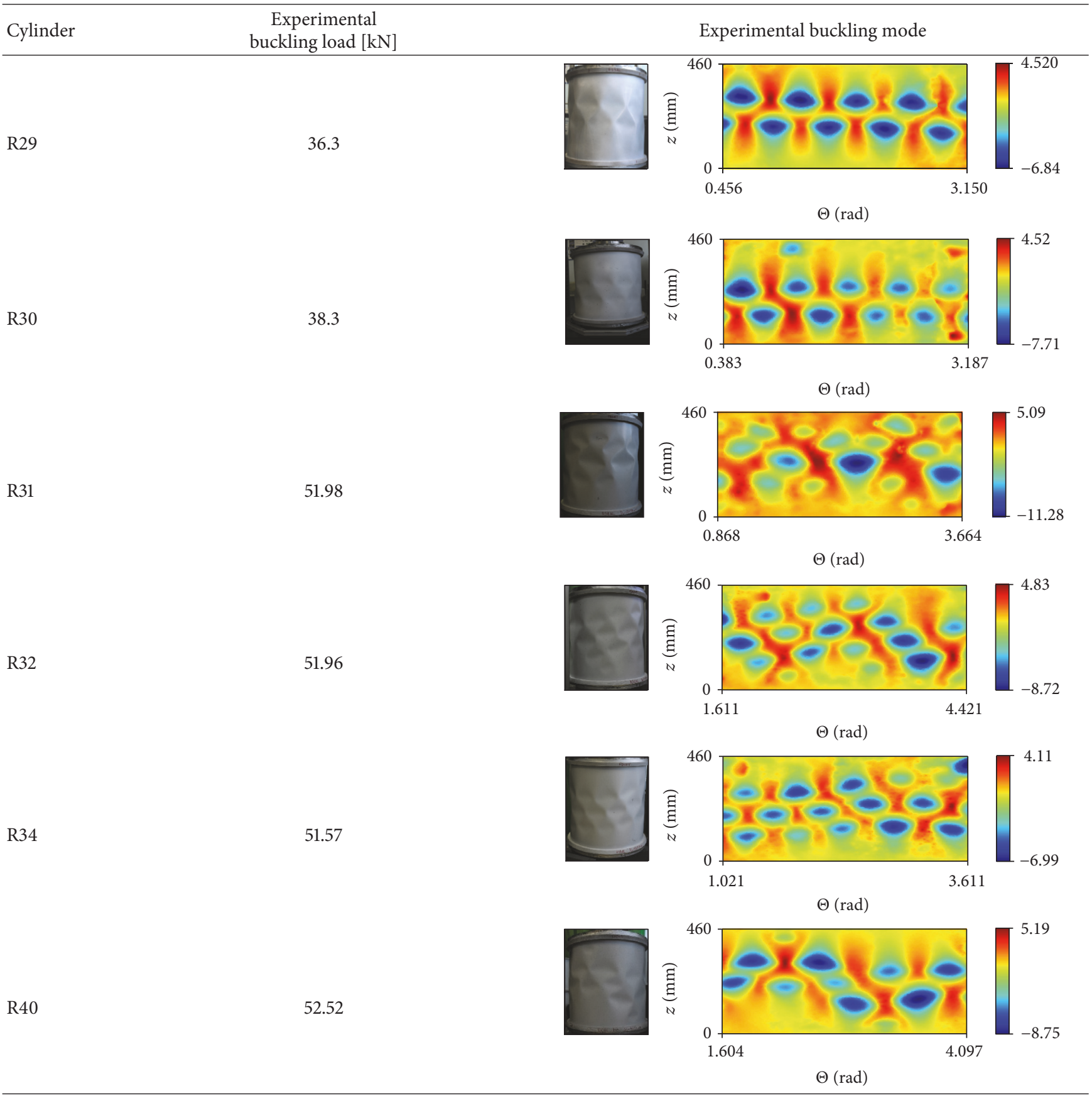

tested are summarized in Table 2 for intact shells and in Table 3 for shells with cutouts. If a local bucking at the cutout was observed preceding the global one, the local buckling load is given in brackets in Table 3 .

The buckling mode shape patterns shown in Tables 2 and 3 were obtained by a photogrammetry technique. The method is based on reconstructing of the $3 \mathrm{D}$ shape of an object using a number of digital camera shots at different angles around the circumference. In this particular case, due to the tight space between test frame columns and the specimen, only a sector of about $1 / 3$ of the shell could be represented in the open plot, usually front and back sectors. The accuracy of determining the out-of-plane displacement magnitude is highly dependent on the number of shots taken and quality of the optical system used. Since there was no straightforward method of calibration available for this technique, the measured magnitudes should be used only for purposes of comparative analysis.

The intact shells R31, R32, R34, and R40, tested with the lower plate supported as shown in Figure 6(a), exhibited very close buckling loads at $52.0 \pm .4 \mathrm{kN}$. Shells R29 and R30 possessed larger geometrical imperfections than the rest, 
TABLE 3: Experimental buckling loads and mode shapes of shells with cutouts.

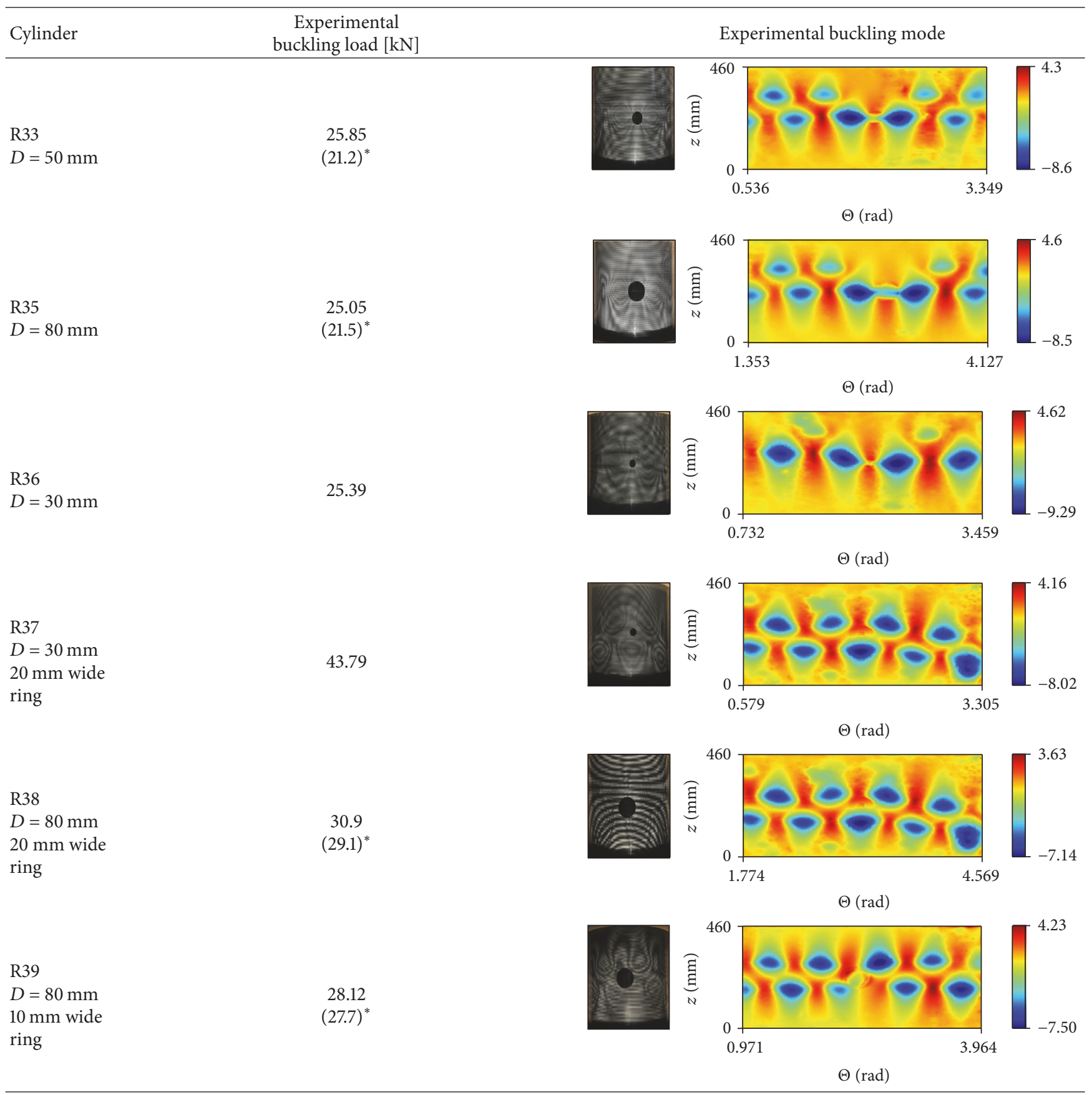

${ }^{*}$ Load at the onset of local buckling.

which was likely the cause of their lower buckling load of ca. $37 \mathrm{kN}$ reported in Table 2.

It is seen in Table 3 that shells with cutouts lacking reinforcement exhibited very close buckling loads of ca. $25 \mathrm{kN}$ for cutout diameters ranging from 30 to $80 \mathrm{~mm}$. Adding a $10 \mathrm{~mm}$ wide reinforcement layer to a shell with $80 \mathrm{~mm}$ cutout increased the critical load by about $10 \%$, while a $20 \mathrm{~mm}$ wide reinforcement patch applied to a $30 \mathrm{~mm}$ cutout elevated buckling load by more than $70 \%$.
It should be noted that the experimental results of the effect cutout on buckling load reported above are in close agreement with those of other authors that have studied this phenomenon. For instance, following the work presented by Toda [23], the authors evaluated the reinforcement ratio of the shells $\gamma$ :

$$
\gamma=\frac{W}{W_{0}}
$$


TABLE 4: Numerical buckling load prediction and VCT results for shells without cutouts.

\begin{tabular}{|c|c|c|c|c|c|c|}
\hline Cylinder & $\begin{array}{c}\text { Experimental } \\
\text { buckling load } \\
{[\mathrm{kN}]}\end{array}$ & $\begin{array}{c}\text { Numerical } \\
\text { predicted } \\
\text { buckling load } \\
{[\mathrm{kN}] \mathrm{RBC} / \mathrm{CBC}}\end{array}$ & $\begin{array}{l}\text { Deviation from } \\
\text { experimental } \\
\text { results [\%] } \\
\text { RBC/CBC }\end{array}$ & $\begin{array}{c}\mathrm{KDF} \\
\mathrm{EXP} / \mathrm{RBC} / \mathrm{CBC}\end{array}$ & $\begin{array}{c}\text { Predicted } \\
\text { buckling load by } \\
\text { VCT }[\mathrm{kN}]\end{array}$ & $\begin{array}{l}\text { Deviation from } \\
\text { experimental } \\
\text { results [\%] }\end{array}$ \\
\hline R29 & 36.33 & $36.45^{*}$ & $0.31^{*}$ & $0.54 /-/ 0.55$ & 38.16 & -5.04 \\
\hline R30 & 38.32 & $44.96^{*}$ & $14.8^{*}$ & $0.57 /-/ 0.67$ & 38.36 & -0.13 \\
\hline R31 & 51.98 & $49.76 / 51.08$ & $-4.5 /-1.8$ & $0.78 / 0.75 / 0.77$ & 46.08 & 11.35 \\
\hline R32 & 51.96 & $49.07 / 49.51$ & $-5.9 /-5.0$ & $0.78 / 0.74 / 0.74$ & 52.71 & -1.44 \\
\hline R34 & 51.57 & $51.70 / 52.39$ & $0.3 / 1.6$ & $0.77 / 0.77 / 0.78$ & 53.36 & -3.47 \\
\hline $\mathrm{R} 40$ & 52.52 & $46.42 / 48.45$ & $-13.1 /-7.5$ & $0.79 / 0.7 / 0.73$ & 40.21 & 23.44 \\
\hline
\end{tabular}

${ }^{*} \mathrm{CBC}$ boundary conditions.

where $W$ is the volume of stiffening and $W_{0}$ is the volume of the shell wall removed by the cutout. The unstiffened cylinders R33, R35, and R36 had $\gamma=0$ due to lack of reinforcement. On the other hand, $\gamma$ values for cylinders R37, R38, and R39 amounted to $0.44,0.062$, and 0.015 , respectively. Toda [23] observed that, in general, the buckling load of an unstiffened cylindrical shell with a reinforced cutout would increase as $\gamma$ increases, which agrees with the results presented herein.

Moreover, Toda also demonstrated that the effect of circular cutouts on buckling loads of cylindrical shells can be determined by the $\alpha$ parameter calculated as

$$
\alpha=\frac{a}{\sqrt{R \cdot t}}
$$

where $a=D / 2, R=D_{\text {shell }} / 2$, and $t$ is the wall thickness of the unstiffened cylinder. For $\alpha<1$, cutouts exhibit no appreciable effect on the buckling strength of the cylinder. Buckling load is greatly reduced in the range of $1<\alpha<2$ and continues to decrease slightly as $\alpha$ increases. Furthermore, increasing the value of $\gamma$ parameter at a fixed $\alpha$ leads to the growth of buckling load (up to that of intact shell for sufficiently large $\gamma$ ) [23]. For our study cases, the $\alpha$ parameter is equal to 1.34 for the cylinder R37 and takes the value of 3.57 for both R38 and R39 cylinders. This, together with the $\gamma$ values of these shells discussed above indicates that the buckling load of R37 should be higher than that of R38 and R39 and also that the buckling load of R38 should exceed that of R39. Such a predicted ranking of buckling loads is confirmed by the experimental results presented in Table 3.

Furthermore, Yilmaz et al. [24] calculated the knockdown factor for the buckling load of unstiffened cylindrical shells with cutouts as a function of the $\alpha$ parameter. Their results agree with Toda's findings [23] and the experimental results presented in Table 3.

5.2. FEM Modeling of Buckling. As the numerical model of cylindrical shells, finite element model composed of SHELL281 shell elements, comprising 130 elements around the circumference and maintaining about $12 \times 12 \mathrm{~mm}$ mesh aspect ratio, was selected based on mesh sensitivity analyses. The experimentally determined mid-surface imperfections, as well as bonding line thickness imperfections, were implemented into the finite element model for each shell.
A nonlinear analysis of buckling was performed, as described in Section 4, considering both RBC and CBC cases of boundary conditions for shells. The resulting buckling loads are presented in Table 4 for intact shells and in Table 5 for shells with cutouts. The knock-down factor (KDF), presented in the Tables, is calculated with respect to the buckling eigenload of a perfect intact cylinder, estimated by linear FEM analysis at $66.74 \mathrm{kN}$.

Comparison of the FEM results of buckling loads with their experimental values revealed that applicability of the simplified CBC was limited to shells which contained only mid-surface and bond-line imperfections. It is seen in Table 4 that in this case both $\mathrm{CBC}$ and RBC yield very close results which, moreover, are also in good agreement with the test results.

For shells containing cutouts, the local reduced stiffness in the cutout region is not adequately allowed for in FEM model with CBC due to the uniform edge translation imposed (i.e., displacement control). By contrast, the RBC model properly reflects such a reduced stiffness via the structural response through bending of the rigid elastic adapter and bending of the loading plates that can actually be considered as cantilever plates. Implementation of the RBC into the FEM model markedly improved prediction accuracy of the buckling load, as seen in Table 5 .

As an example, experimental and predicted load-shortening curves for shells with and without cutouts are presented in Figure 10. Virtually no difference in the predicted shell response under $\mathrm{CBC}$ and $\mathrm{RBC}$ is seen for the intact shell R34 up to buckling. By contrast, for the shell R35 weakened by a cutout, the theoretical load-shortening diagrams diverge markedly upon local buckling of the shell at the cutout, with CRC producing a stiffer response and greater global buckling load. FEM analysis with RBC captures reasonably accurately both the local buckling, manifesting by a slight drop in load with subsequent lower slope of load-shortening diagrams seen in Figure 10(b), and the global buckling.

5.3. Application of VCT. The standard VCT is being applied to structural elements for which the shape of the vibration mode, where the frequency of which is monitored during compressive loading, matches or is close to their buckling mode shape [8]. This is clearly not the case for the first 
TABLE 5: Numerical buckling load prediction and VCT results for shells with cutouts.

\begin{tabular}{|c|c|c|c|c|c|c|}
\hline Cylinder & $\begin{array}{c}\text { Experimental } \\
\text { buckling load } \\
{[\mathrm{kN}]}\end{array}$ & $\begin{array}{c}\text { Numerical } \\
\text { predicted } \\
\text { buckling load } \\
{[\mathrm{kN}] \mathrm{RBC} / \mathrm{CBC}}\end{array}$ & $\begin{array}{c}\text { Deviation from } \\
\text { experimental } \\
\text { results [\%] } \\
\text { RBC/CBC }\end{array}$ & $\begin{array}{c}\text { KDF } \\
\mathrm{EXP} / \mathrm{RBC} / \mathrm{CBC}\end{array}$ & $\begin{array}{c}\text { Predicted } \\
\text { buckling load by } \\
\text { VCT }[\mathrm{kN}]\end{array}$ & $\begin{array}{l}\text { Deviation from } \\
\text { experimental } \\
\text { results [\%] }\end{array}$ \\
\hline R36 & 25.39 & $31.22 / 36.92$ & $18.69 / 31.25$ & $0.38 / 0.47 / 0.55$ & 29.81 & -17.4 \\
\hline R33 & $25.85(21.2)^{*}$ & $28.80 / 36.88$ & $10.22 / 29.90$ & $0.39 / 0.43 / 0.55$ & - & - \\
\hline R35 & $25.05(21.5)^{*}$ & $28.51 / 36.66$ & $12.14 / 31.66$ & $0.38 / 0.43 / 0.55$ & - & - \\
\hline R37 & 43.79 & $47.42 / 49.41$ & $7.64 / 11.37$ & $0.66 / 0.71 / 0.74$ & 41.59 & 5.0 \\
\hline R38 & $27.93(26.76)^{*}$ & $31.48 / 35.10$ & $11.26 / 20.43$ & $0.42 / 0.47 / 0.53$ & - & - \\
\hline R39 & $28.12(27.2)^{*}$ & $31.33 / 38.29$ & $10.24 / 26.58$ & $0.42 / 0.47 / 0.57$ & 24.94 & 11.3 \\
\hline
\end{tabular}

* Load at the onset of local buckling.

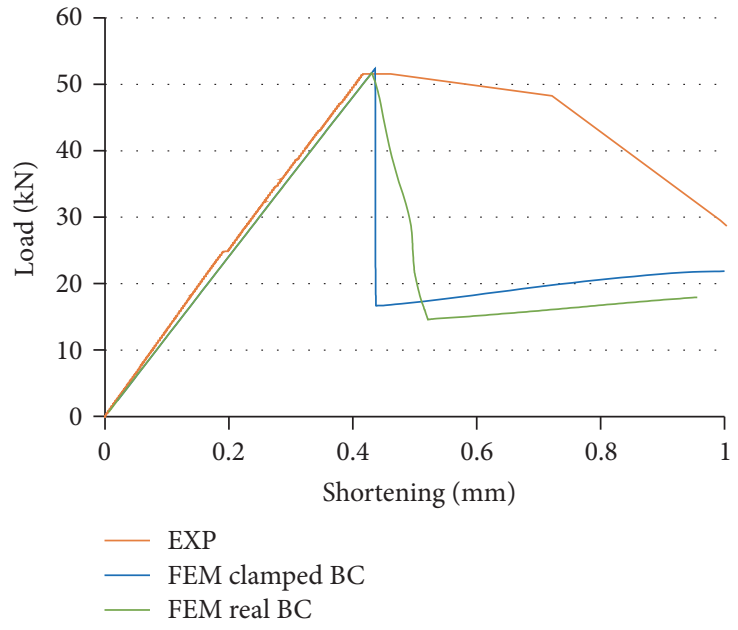

(a)

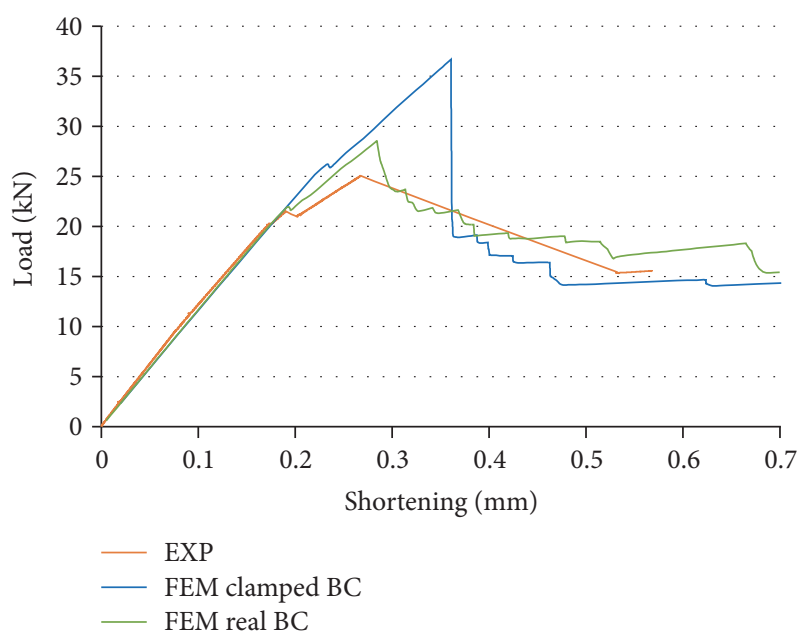

(b)

FIgURE 10: Experimental and predicted load-shortening curves for the shell R34 without cutout (a) and shell R35 with a cutout (b).

vibration mode monitored during axial compression for either the intact cylinders (cf. Figure 8(a) and Table 2) or the cylinders with cutouts (cf. Figure 8(b) and Table 3).

However, the modified VCT developed in [17] allows correlating reduction of the first natural frequency of an unstiffened cylindrical shell under axial compression to the buckling load when the buckling mode differs from the vibration one. In the following, we check the applicability of the modified VCT [17] to the unstiffened aluminium shells.

Natural frequency response of the intact shells, free from loading, is shown in Figure 11(a). Vibration characteristics of the different shells are seen to be rather similar as would be expected for cylinders of the same dimensions and material.

The limited variability present is thought to be stemming mostly from the differences in geometrical mid-surface and bond-line imperfections among shells. The first vibration mode was identified from natural frequency response of each cylinder (Figure 11(a)), and its variation was monitored during axial compressive loading of the shell. The experimentally determined reduction of the vibration frequencies of intact shells with incrementally growing load is presented in Figure 11(b). It is seen that the scatter in the first natural frequency among specimens also decreases with increasing load.

Using the frequency variation data presented in Figure 11(b) and the critical load of a perfect intact cylinder estimated by FEM, the plots of $(1-p)^{2}$ versus $1-f^{2}$ were constructed for the pooled data of shells R31, R32, R34, and R40 characterized by relatively small imperfections and for pooled data of shells R29 and R30 having larger imperfections. (Each of the two sets of shells mentioned was produced under the same conditions resulting in close imperfection signatures within a set, which allowed considering the shells as nominally identical within each set.) The respective plots are shown in Figure 12 together with a second-order fitting curve as stipulated by the modified VCT [17]. From the minimum of the approximating secondorder polynomial, the numerical value of the factor $\xi^{2}$ characterizing the reduction of buckling load caused by shell imperfections was determined as $\xi^{2}=0.0609$ for the set of Figure 12(a) and $\xi^{2}=0.1824$ for the set of Figure 12(b). Buckling load predicted by the modified VCT using (2) for the shells R31-R40 amounted to $50.27 \mathrm{kN}$, which is very close to the average experimental buckling load $52.0 \mathrm{kN}$ of 


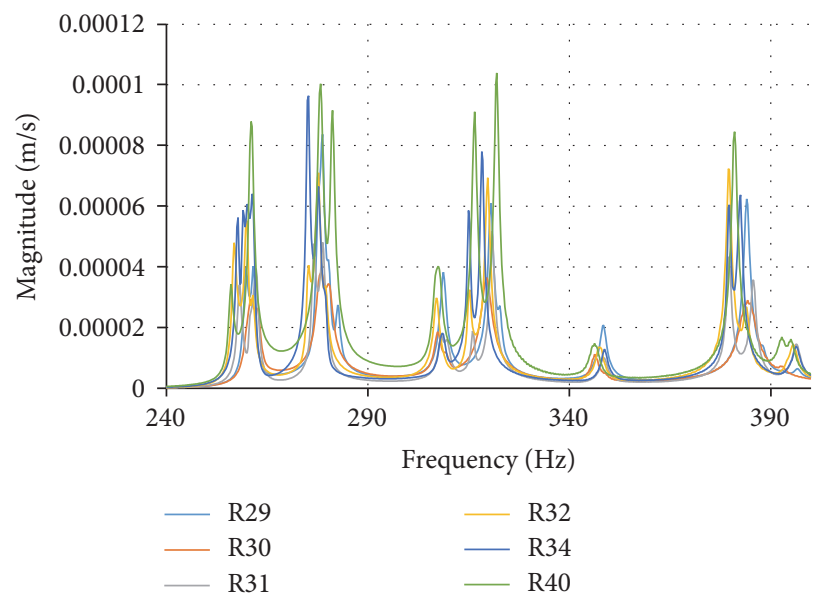

(a)

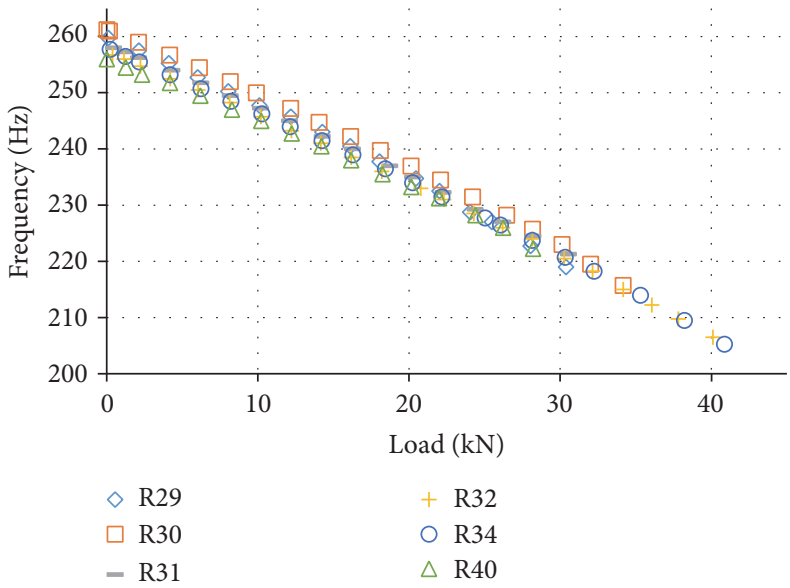

(b)

FIGURE 11: Natural frequency response of intact unloaded cylinders (a) and reduction of the first natural frequency with increasing axial load (b).

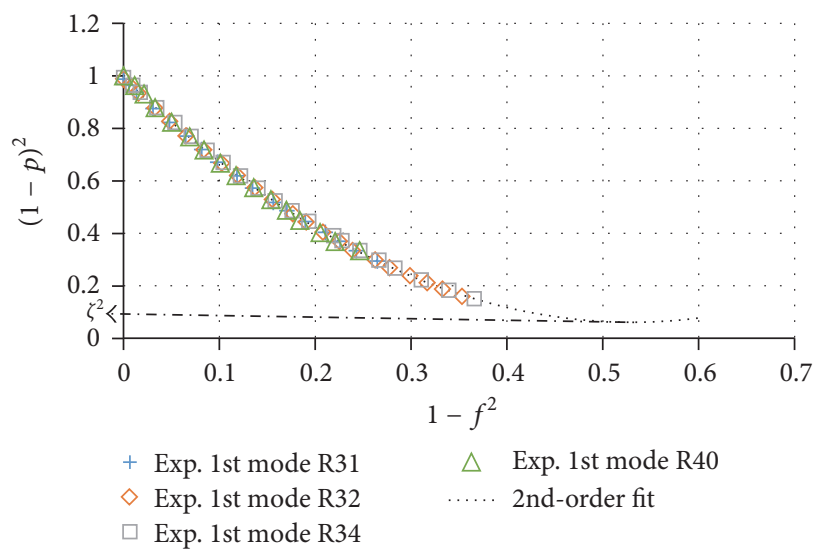

(a)

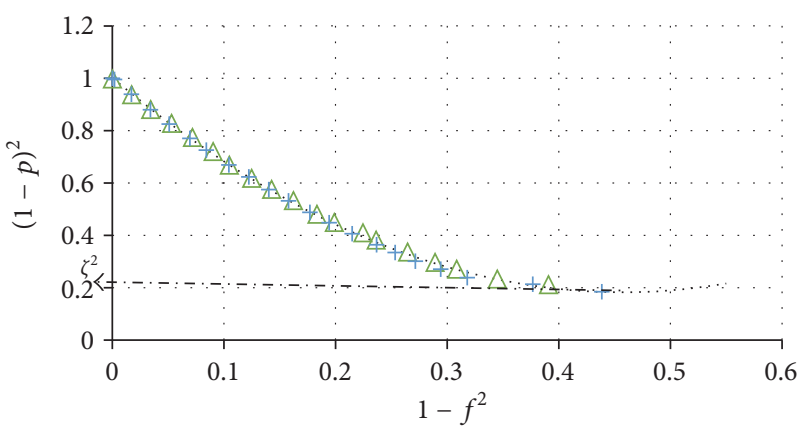

$\triangle \quad$ Exp. 1st mode R29

$+\quad$ Exp. 1st mode R30

.... 2nd-order fit

(b)

Figure 12: Plot of $(1-p)^{2}$ as a function of $1-f^{2}$ and the second-order fit for the sets of cylinders with comparatively small (a) and larger (b) imperfections.

these shells. Similarly, a good agreement of the predicted, $38.2 \mathrm{kN}$, and average experimental, $37.3 \mathrm{kN}$, buckling load was obtained for the shells R29 and R30 with larger imperfections. Notably, comparable accuracy of the VCT approach has also been reported in [18] for unstiffened cylindrical composite shells.

Such a good predictive capacity lends credence to the semiempirical VCT considered, but it should also be noted that capturing the vibration response of a set of nominally identical specimens up to a relatively high level of applied force $P$ may not always be feasible in practice. In order to evaluate the effect of maximum load used in VCT on the prediction accuracy of buckling load, the latter was evaluated by the modified VCT for each specimen and load increment separately. The results are presented in Figure 13 in terms of the relative accuracy of prediction, characterized by the ratio of predicted and experimental buckling loads $P_{\text {pred }} / P_{\text {exp }}$, as

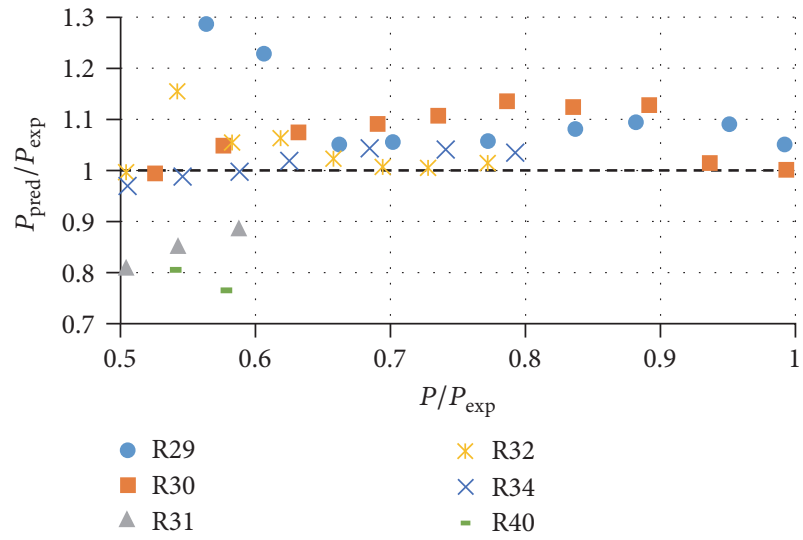

FIGURE 13: Predicted buckling load $P_{\text {pred }}$ of an intact shell versus the maximum applied load $P$ used in VCT, normalized by experimental buckling load of the shell $P_{\text {exp }}$. 


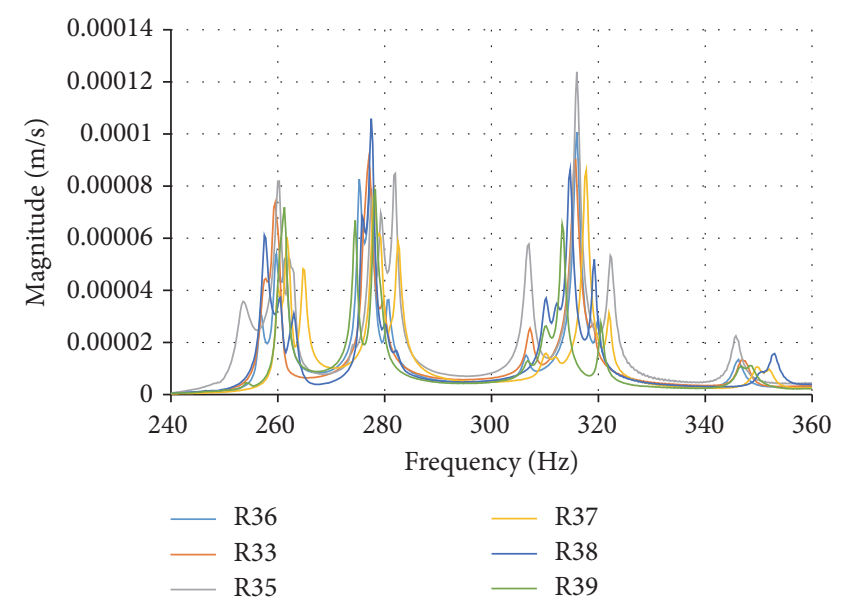

(a)

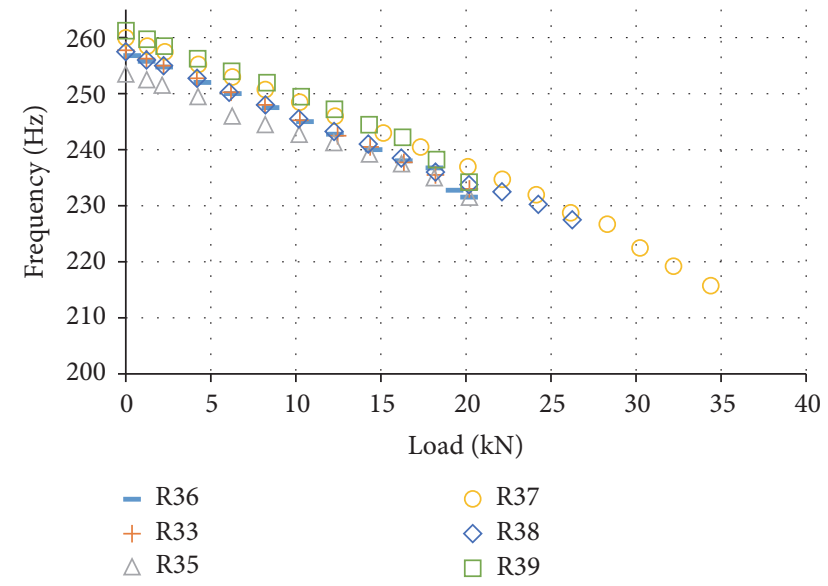

(b)

FIGURE 14: Natural frequency response of unloaded cylinders with cutouts (a) and reduction of the first natural frequency with increasing axial load (b).

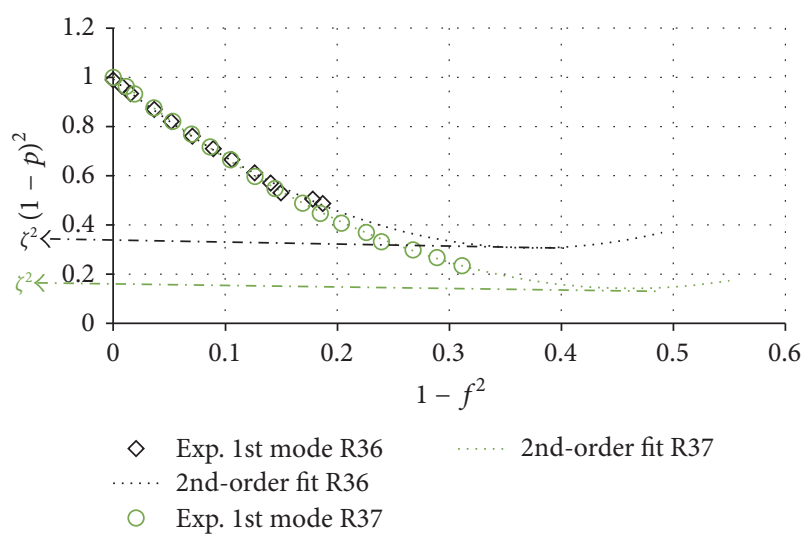

(a)

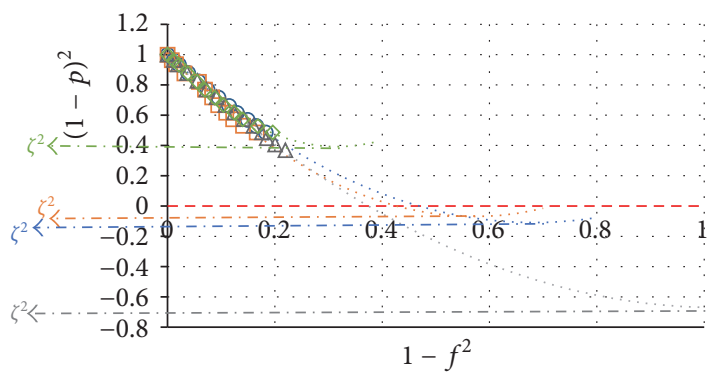

$\begin{array}{clcl}\circ & \text { Exp. 1st mode R33 } & \Delta & \text { Exp. 1st mode R38 } \\ \cdots \cdots & \text { 2nd-order fit R33 } & \cdots & \text { 2nd-order fit R38 } \\ \square & \text { Exp. 1st mode R35 } & \diamond & \text { Exp. 1st mode R39 } \\ \cdots & \text { 2nd-order fit R35 } & \cdots & \text { 2nd-order fit R39 }\end{array}$

(b)

FIGURE 15: Plot of $(1-p)^{2}$ as a function of $1-f^{2}$ and the second-order fit for cylinders with cutouts that failed without (a) and with local buckling preceding global instability (b).

a function of the maximum load used in VCT expressed as a fraction of the buckling load, $P / P_{\exp }$. Data for $P / P_{\exp }>$ 0.5 only are plotted since the VCT approach considered has been shown to yield insufficiently accurate results for smaller values of the maximum normalized load [18]. The numerical values of $P_{\text {pred }}$ estimated using data up to the maximum applied load $P$ for each shell are also given in Table 4 .

It is seen in Figure 13 that the relative error of prediction can reach up to $30 \%$ if $P$ is limited by $60 \%$ of $P_{\text {exp }}$. However, the accuracy of VCT can be markedly improved by extending the loading range: when $P / P_{\exp } \geq 0.62$, the predicted buckling load differs by less than $10 \%$ from the experimental one for five of the six cylinders tested; even for the outlier R30, the error does not exceed $15 \%$.

In order to further increase the accuracy of prediction, simultaneous monitoring of evolution of several vibration modes under axial load could be considered in the modified VCT. The results reported in [19] revealed that that using the second vibration mode for estimation of the buckling load provided closer conservative prediction in some cases. Combining the data for several vibration modes of the same specimen may facilitate both accuracy and robustness of VCT, and validation of such an approach is the subject of further research.

Natural frequency response of free shells with cutouts shown in Figure 14(a) exhibited considerable variability among shells, presumably caused by differing diameters of the open holes and the reinforcement rings. The variability also persisted when the shells were subjected to axial loading, as seen in Figure 14(b) presenting experimentally determined reduction of the first natural frequency of each shell as a function of the axial compressive load.

Experimental results of the variation of frequency with axial load were normalized as above, obtaining $(1-p)^{2}$ versus $1-f^{2}$ data for each shell which were approximated by a second-order polynomial. The data and the best-fit polynomials, extrapolated in order to graphically reveal their minima, are plotted in Figure 15. It is seen that, for part of the cylinders 
with cutouts, the modified VCT produced negative values of $\xi^{2}$ which is physically inadmissible. The reason the modified VCT failed for specimens with open holes is apparently related to a more complicated evolution of instability in the presence of a cutout. Specifically, for majority of the cylinders tested, a local buckling at the cutout was observed to precede the global one. VCT plots for these specimens are presented in Figure 15(b).

Appearance of the local buckling was associated with larger cutouts as follows from Table 3. Even for the shells R36, R37, and R39 for which the modified VCT could formally be applied since positive values of $\xi^{2}$ were obtained, the accuracy of prediction was not uniform; see Table 5 .

Apparently, further work is needed to develop a nondestructive test method applicable to weakened shells exhibiting stable local buckling modes preceding the global buckling. A potentially fruitful alternative to monitoring the vibration response of the whole shell under load could be exploring the variation of local characteristics of the shell at the spots likely to undergo instability [25]. Additional tests are currently under development to further validate this proposed approach.

\section{Conclusions}

In general, the presence of a circular open-hole cutout was found to reduce the buckling load in axial compression of thin-wall unstiffened cylindrical shells produced from aluminium sheet by up to $50 \%$ with respect to intact shells. Reinforcement by a ring of the same material, adhesively bonded around cutout, alleviated its detrimental effect, and wider reinforcement rings lead to smaller reduction in buckling load due to cutout.

The modified VCT has been demonstrated to be an efficient tool for nondestructive prediction of the load-carrying capacity of intact shells. The discrepancy of the predicted and experimental critical load of less than about $10 \%$ was attained when the reduction of fundamental frequency of a shell was monitored under axial loads in excess of $60 \%$ of the buckling load. By contrast, appearance of a local buckling at the cutout, preceding the global buckling of a shell, was found to invalidate the considered VCT for shells with holes. Notably, a good agreement between the experimental and predicted buckling load from VCT was observed for the R37 cylinder possessing a relatively high stiffening ratio $\gamma$ and low $\alpha$ parameter value. Further testing should be conducted in order to seek a correlation between these two parameters and the range of applicability of VCT for cylindrical shells with reinforced cutouts.

Implementing the experimentally determined geometrical imperfections of shells in a nonlinear analysis of instability by FEM enabled accurate prediction of buckling load of the intact shells, with the maximum error less than $15 \%$. For shells with cutouts, the importance of applying the actual boundary conditions, allowing for deformations of the loading set-up during tests, was revealed. Specifically, the buckling load was overestimated by up to $31 \%$ under simplified clamped boundary conditions, while including the appropriate elements of the loading rig in the FEM analysis markedly increased the accuracy of prediction.

\section{Disclosure}

The information in this paper reflects only the authors' views and the European Community is not liable for any use that may be made of the information contained therein.

\section{Conflicts of Interest}

The authors have no conflicts of interest as the software and hardware are developed by authors of this manuscript.

\section{Acknowledgments}

The research leading to these results has received partial funding from the European Community's Seventh Framework Programme (FP7/2007-2013), Grant Agreement no. 282522 (http://www.desicos.eu). The authors also acknowledge the National Council for Scientific and Technological Development $(\mathrm{CNPq})$ for the financial support (Grant no. 300893/2015-9).

\section{References}

[1] R. Degenhardt, S. G. P. Castro, M. A. Arbelo, R. Zimmerman, R. Khakimova, and A. Kling, "Future structural stability design for composite space and airframe structures," Thin-Walled Structures, vol. 81, pp. 29-38, 2014.

[2] B. Kriegesmann, E. L. Jansen, and R. Rolfes, "Design of cylindrical shells using the Single Perturbation Load Approach Potentials and application limits," Thin-Walled Structures, vol. 108, pp. 369-380, 2016.

[3] H. N. R. Wagner, C. Hühne, S. Niemann, and R. Khakimova, "Robust design criterion for axially loaded cylindrical shells Simulation and Validation," Thin-Walled Structures, vol. 115, pp. 154-162, 2017.

[4] H. Wagner, C. Hühne, and S. Niemann, "Robust knockdown factors for the design of axially loaded cylindrical and conical composite shells - Development and Validation," Composite Structures, vol. 173, pp. 281-303, 2017.

[5] S. G. P. Castro, R. Zimmermann, M. A. Arbelo, and R. Degenhardt, "Exploring the constancy of the global buckling load after a critical geometric imperfection level in thin-walled cylindrical shells for less conservative knock-down factors," Thin-Walled Structures, vol. 72, pp. 76-87, 2013.

[6] S. G. P. Castro, R. Zimmermann, M. A. Arbelo, R. Khakimova, M. W. Hilburger, and R. Degenhardt, "Geometric imperfections and lower-bound methods used to calculate knock-down factors for axially compressed composite cylindrical shells," ThinWalled Structures, vol. 74, pp. 118-132, 2014.

[7] M. A. Arbelo, R. Degenhardt, S. G. P. Castro, and R. Zimmermann, "Numerical characterization of imperfection sensitive composite structures," Composite Structures, vol. 108, no. 1, pp. 295-303, 2014.

[8] "Vibration Correlation Techniques," in Buckling Experiments, Experimental Methods in Buckling of Thin-Walled Structures, vol. 2, Chapter 15, pp. 1244-1284, John Wiley Sons, New York, NY, USA, 2002.

[9] L. N. Virgin, Vibration of Axially-Loaded Structures, Cambridge University Press, North Carolina, NC, USA, 2007. 
[10] H. Abramovich, D. Govich, and A. Grunwald, "Buckling prediction of panels using the vibration correlation technique," Progress in Aerospace Sciences, vol. 78, pp. 62-73, 2015.

[11] E. L. Jansen, H. Abramovich, and R. Rolfes, “The direct prediction of buckling loads of shells under axial compression using VCT - Towards an upgraded approach," in Proceedings of the 29th Congress of the International Council of the Aeronautical Sciences (ICAS '14), September 2014.

[12] M. A. Souza, W. C. Fok, and A. C. Walker, "Review of experimental techniques for thin-walled structures liable to buckling, part I-neutral and unstable buckling," Experimental Techniques, vol. 7, no. 9, pp. 21-25, 1983.

[13] M. A. Souza, "The effects of initial imperfection and changing support conditions on the vibration of structural elements liable to buckling," Thin-Walled Structures, vol. 5, no. 6, pp. 411-423, 1987.

[14] M. A. Souza and L. M. B. Assaid, "A new technique for the prediction of buckling loads from nondestructive vibration tests," Experimental Mechanics, vol. 31, no. 2, pp. 93-97, 1991.

[15] M. A. Souza, "Coupled dynamic instability of thin-walled structural systems," Thin-Walled Structures, vol. 20, no. 1-4, pp. 139149, 1994.

[16] E. Skukis, K. Kalnins, and A. Chate, "Preliminary assessment of correlation between vibrations and buckling load of stainless steel cylinders," in Proceedings of the 10th Jubilee Conference on "Shell Structures: Theory and Applications" (SSTA '13), pp. 325328, October 2013.

[17] M. A. Arbelo, S. F. M. de Almeida, M. V. Donadon et al., "Vibration correlation technique for the estimation of real boundary conditions and buckling load of unstiffened plates and cylindrical shells," Thin-Walled Structures, vol. 79, pp. 119-128, 2014.

[18] M. A. Arbelo, K. Kalnins, O. Ozolins, E. Skukis, S. G. P. Castro, and R. Degenhardt, "Experimental and numerical estimation of buckling load on unstiffened cylindrical shells using a vibration correlation technique," Thin-Walled Structures, vol. 94, pp. 273279, 2015.

[19] K. Kalnins, M. A. Arbelo, O. Ozolins, E. Skukis, S. G. P. Castro, and R. Degenhardt, "Experimental nondestructive test for estimation of buckling load on unstiffened cylindrical shells using vibration correlation technique," Shock and Vibration, vol. 2015, Article ID 729684, 8 pages, 2015.

[20] E. Skukis, O. Ozolins, K. Kalnins, and M. A. Arbelo, "Experimental Test for Estimation of Buckling Load on Unstiffened Cylindrical shells by Vibration Correlation Technique," in Proceedings of the 12th International Conference Modern Building Materials, Structures and Techniques (MBMST '16), vol. 172, pp. 1023-1030, 2017.

[21] H. Abramovich, K. Kalnins, and A. Wieder, "Test results on the stability and vibrations of composite shells," in Stability and Vibrations of Thin Walled Composite Structures, pp. 619-691, 2017.

[22] ANSYS ${ }^{\circledR}$ Academic Research, Release 16.2.

[23] S. Toda, "Buckling of cylinders with cutouts under axial compression - Experimental results are presented for circular cylinderical shells with both reinforced and unreinforced holes under axial compression," Experimental Mechanics, vol. 23, no. 4, pp. 414-417, 1983.

[24] H. Yılmaz, İ. Kocabaş, and E. Özyurt, "Empirical equations to estimate non-linear collapse of medium-length cylindrical shells with circular cutouts," Thin-Walled Structures, vol. 119, pp. 868-878, 2017.
[25] W. H. Horton, E. M. Nassar, and M. K. Singhal, "Determination of the critical loads of shells by nondestructive methods - The critical axial loads for conventional cylindrical-shell bodies are experimentally determined by measuring the static and dynamic properties of the shell wall at low levels of the applied loading," Experimental Mechanics, vol. 17, no. 4, pp. 154-160, 1977. 


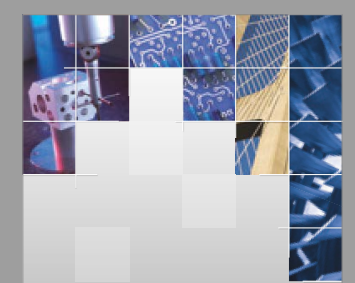

\section{Enfincering}
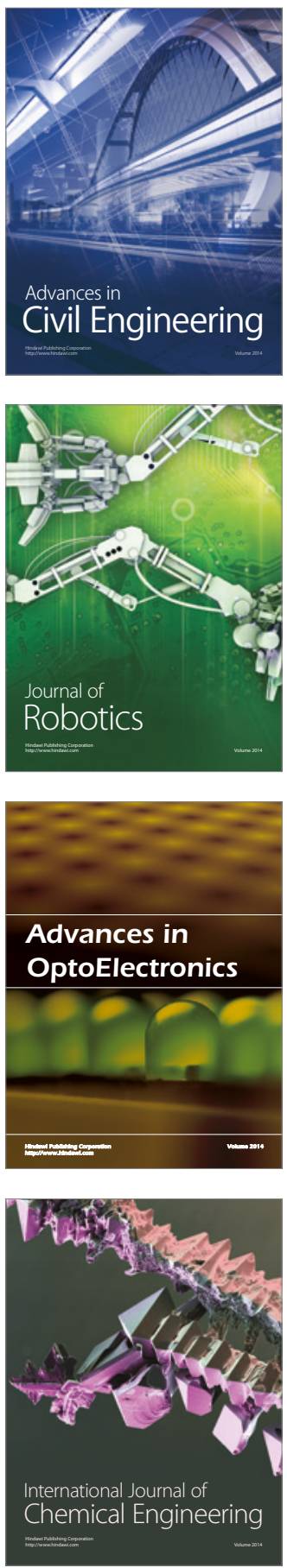

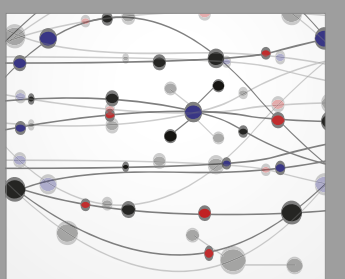

The Scientific World Journal

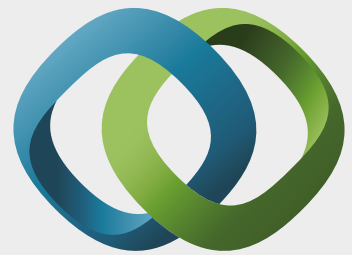

\section{Hindawi}

Submit your manuscripts at

https://www.hindawi.com
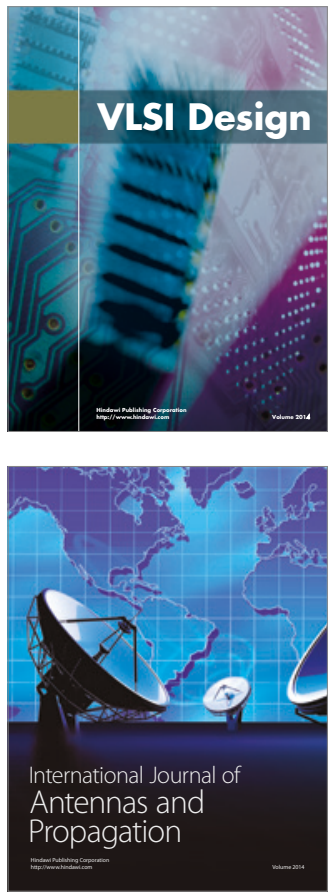

\section{Rotating}

Machinery
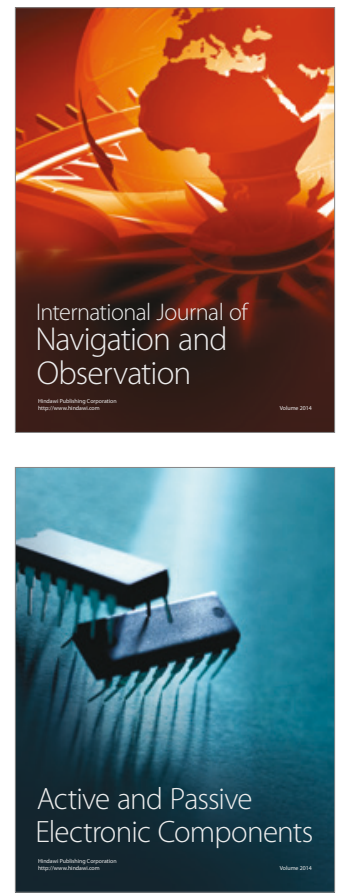
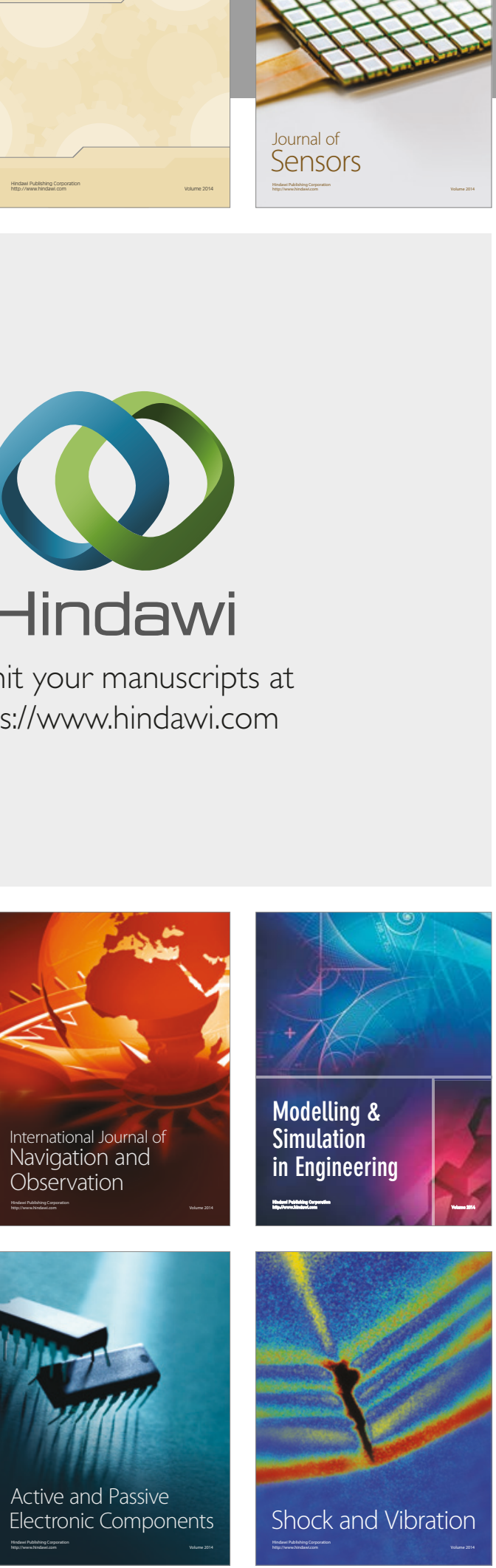
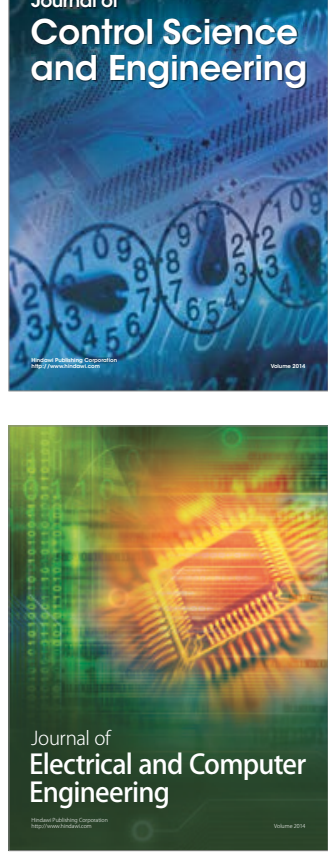

Distributed

Journal of

Control Science

and Engineering
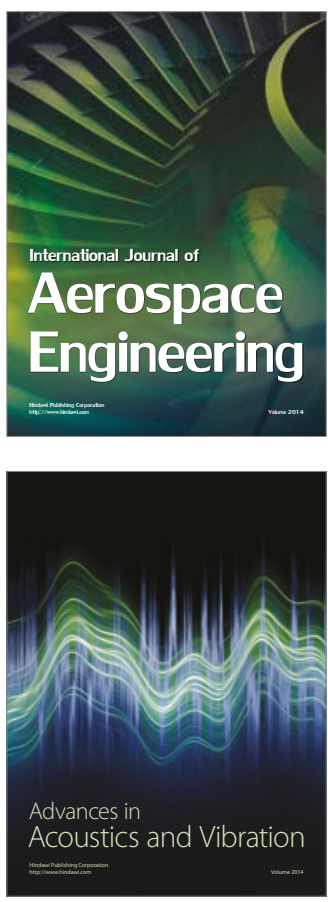

Sensor Networks 